\title{
Fast curing ethylene vinyl acetate films with dual curing agent towards application as encapsulation materials for photovoltaic modules
}

\author{
H-Y.Xue ${ }^{1,2}$, W-H. Ruan ${ }^{2 *}$, M-Q. Zhang ${ }^{2}$, M-Z. Rong ${ }^{2}$ \\ ${ }^{1}$ Key Laboratory for Polymeric Composite and Functional Materials of Ministry of Education, Zhongshan University, \\ 510275 Guangzhou, P. R. China \\ ${ }^{2}$ Materials Science Institute, The School of Chemistry and Chemical Engineering, Zhongshan University, 510275 \\ Guangzhou, P. R. China
}

Received 7 August 2013; accepted in revised form 8 October 2013

\begin{abstract}
To speed up curing of ethylene vinyl acetate (EVA) films as encapsulation materials for photovoltaic modules, a dual curing agent of benzoyl peroxide (BPO) and butylperoxy 2-ethylhexyl carbonate (TBEC) was introduced in this work. The experimental results indicated that for the weight ratio of BPO/TBEC of $0.6 / 2.4$, over $80 \%$ gel content of EVA was yielded after curing at $130^{\circ} \mathrm{C}$ for $12 \mathrm{~min}$. Compared with the case of single curing agent, the present one obviously operated at much lower temperature with faster rate. By carefully studying the influence of curing agent proportion and curing conditions on gel content of EVA films, as well as rheology and curing kinetics, the mechanism involved was analyzed and verified. The results are believed to be useful for developing new curing system of EVA encapsulation films with improved processability.
\end{abstract}

Keywords: industrial applications, ethylene vinyl acetate (EVA) films, curing, dual curing agent, properties

\section{Introduction}

Silicon wafers in solar cells (also called photovoltaic (PV) modules) are generally embedded in encapsulation polymer films by either glass/glass or glass/plastic technology. The latter plays a vital role to bond different components. So far, the most common encapsulation material for PV modules is ethylene vinyl acetate (EVA) because of its balanced performance [1-3]. To provide high transparency, electrical insulation and mechanical stability for photovoltaic system, EVA films have to be cured during encapsulation [4], which has a direct impact on the production efficiency and products quality. It is worth noting that curing of EVA is quite timeconsuming. When dicumyl peroxide (DCP) acts as curing agent, the lamination process typically pro- ceeds under vacuum and high pressure at $150-160^{\circ} \mathrm{C}$ for a while ( $>30 \mathrm{~min}$ ) [5]. To accelerate curing of EVA films, efforts to develop advanced curing agent have been made. Butylperoxy 2-ethylhexyl carbonate (TBEC), for example, was found to be able to decrease the curing temperature and time to $145^{\circ} \mathrm{C}$ and 20-25 min, respectively [6]. In addition, benzoyl peroxide (BPO) was applied, which allowed for curing below $100^{\circ} \mathrm{C}$. Nevertheless, the high exhaust rate of BPO caused damage to surface roughness and pre-curing would occur as decomposition temperature of BPO was close to the processing temperature.

Meanwhile, Beheshty et al. [7] studied curing of unsaturated polyester with acetyl acetone peroxide (AAP) solution as low temperature curing agent

\footnotetext{
${ }^{\text {*Corresponding author, e-mail: cesrwh@mail.sysu.edu.cn }}$ (C) BME-PT
} 
and t-butyl perbenzoate (TBPB) as high temperature curing agent. The results showed that the curing temperature was reduced by $10^{\circ} \mathrm{C}$ and the curing speed was increased. Firstly, the low temperature curing agent was decomposed to initiate the curing, increasing local temperature of the polymer owing to the exotherm. Then, decomposition of the high temperature curing agent is triggered, which further increase the curing rate [8]. Xia and Cook [9] also used dual radical initiator system of two peroxides with different initiation rates to polymerize nona-ethylene glycol dimethacrylate. The maximum heat flow was reduced and polymerization process was spread over a broader range of temperature without affecting the degree of curing.

The above review suggests that dual curing agent rather than single curing agent would be more effective for accelerating curing of EVA films. In this context, we combine BPO and TBEC into one group. It is hoped that the BPO could induce crosslinking reaction of EVA at lower temperature, while TBEC takes effect at higher temperature as mentioned above. Hereinafter, the influences of compounding proportion and curing conditions on gel content of EVA films are investigated to verify our design. Kinetics and rheology of curing as well as optical property and storage performance of EVA films are also studied. The outcomes of this work will be helpful for industrial applications in practice.

\section{Experimental section}

\subsection{Materials}

Granulated EVA copolymer with 32\% vinyl acetate (VA) content (EVA MA-10, melt flow index = $40 \mathrm{~g} / 10 \mathrm{~min}$, melting point $=65^{\circ} \mathrm{C}$, density $=$ $0.950 \mathrm{~g} / \mathrm{cm}^{3}$ ) was supplied by Polyolefin Company (Singapore) Pte, Ltd. The low temperature curing agent BPO was purchased from Shanghai Aladdin, China. The high temperature curing agent TBEC was bought from Shangyu Shaofeng Chemical Co., Ltd., China. The anti-ageing system of EVA encapsulation films was provided by cooperative enterprise [10]. Ultraviolet absorbent 329, antioxidant 1010 and light stabilizer 944 were also bought from Shangyu Shaofeng Chemical Co., Ltd., China.

\subsection{Preparation of EVA films}

EVA films containing BPO/TBEC were prepared as follows. EVA granules ( $45.0 \mathrm{~g}$ ) and a certain portion of the additives were mixed by a HAAKE mixer (RC300p, HAAKE, Germany) at $70^{\circ} \mathrm{C}$ with a rotor speed of $50 \mathrm{r} / \mathrm{min}$. Afterwards, the compounds were pressed into films $0.40 \mathrm{~mm}$ thick (with a $0.15 \mathrm{~mm}$ gas exhaust layer) by a laminator (CHTECH, CH0205, China). For comparison, EVA films with single curing agent TBEC were fabricated under the same way.

The curing of EVA films took place in a RGFDY002 solar cell laminator (Jinan Rui PV Machinery Co., Ltd., China) in vacuum. Effects of curing time and temperature were studied.

\subsection{Characterization}

Cured EVA films were extracted by xylene at $150^{\circ} \mathrm{C}$ for $24 \mathrm{~h}$ (ASTM D5492). After extraction, the samples were dried a vacuum at $80^{\circ} \mathrm{C}$ for $24 \mathrm{~h}$. Gel content, $G C$, was calculated from Equation (1):

$G C=\frac{W_{1}-W_{2}}{W_{1}} \cdot 100 \%$

where $W_{1}$ denotes the weight of EVA films before extraction, $W_{2}$ the weight of EVA films after extraction. To check stability of the curing performance, the EVA films containing curing agent were stored at $60^{\circ} \mathrm{C}$ for a month and then cured. Then, gel content was determined by the xylene extraction.

To monitor the curing process, EVA films with the curing agents were mixed in a HAAKE torque rheometer (RC300p, HAAKE, Germany) for $20 \mathrm{~min}$ at different temperatures $\left(110,120,130\right.$ and $\left.140^{\circ} \mathrm{C}\right)$ with a rotor speed of $30 \mathrm{r} / \mathrm{min}$. Torque-time and temperature-time curves were recorded.

Kinetics study of curing of EVA films was carried out by differential scanning calorimeter (DSC) with TA instruments Q10 under nitrogen atmosphere at different heating rates $\left(1,3,5,7\right.$ and $\left.9^{\circ} \mathrm{C} / \mathrm{min}\right)$ from -50 to $250^{\circ} \mathrm{C}$. The weights of all the specimens were approximately $3-5 \mathrm{mg}$.

A transmittance haze meter (WGT-S, Bogoo, China) was used to measure light-transmittance and haze values of cured EVA films according to the method of ASTM D 1003: 2007 [11].

The storage performance test is according to the following steps. After been stored at $60^{\circ} \mathrm{C}$ for a month, the EVA films were cured by a solar cell laminator (Jinan Rui PV Machinery Co., Ltd., RGFDY-002) in a vacuum. The gel contents $(G C \%)$ of EVA films were tested by xylene extraction. 


\section{Results and discussion}

Crosslinked EVA chains are insoluble in hot xylene, while the non-crosslinked ones are dissolvable. On the basis of this principle, the gel content measurement not only reflects crosslinking degree of cured EVA films, but also can be used to optimize curing conditions. Figure 1 shows the dependence of gel content of cured EVA films on relative proportions of the dual curing agent. It is seen that under the curing temperature of $130^{\circ} \mathrm{C}$, the gel content of the cured EVA films with BPO/TBEC ratio of 0.8/2.2 is about $85 \%$. With a rise in the concentration of TBEC, the gel content gradually decreases. Similar trend

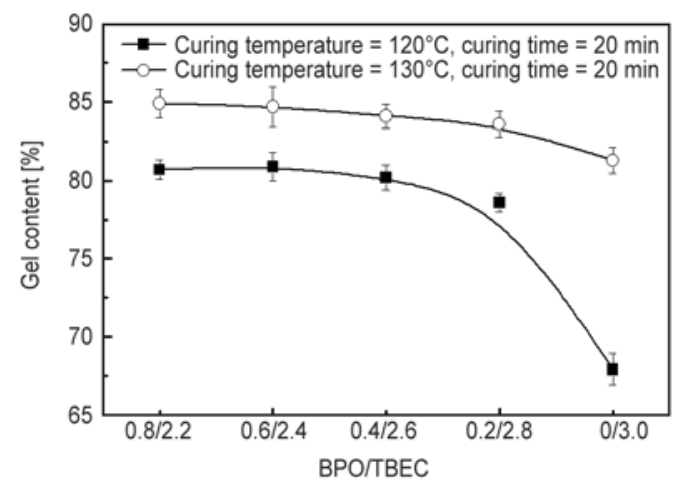

Figure 1. Gel contents of EVA films cured by BPO/TBEC at different temperatures as a function of $\mathrm{BPO} /$ TBEC weight ratio
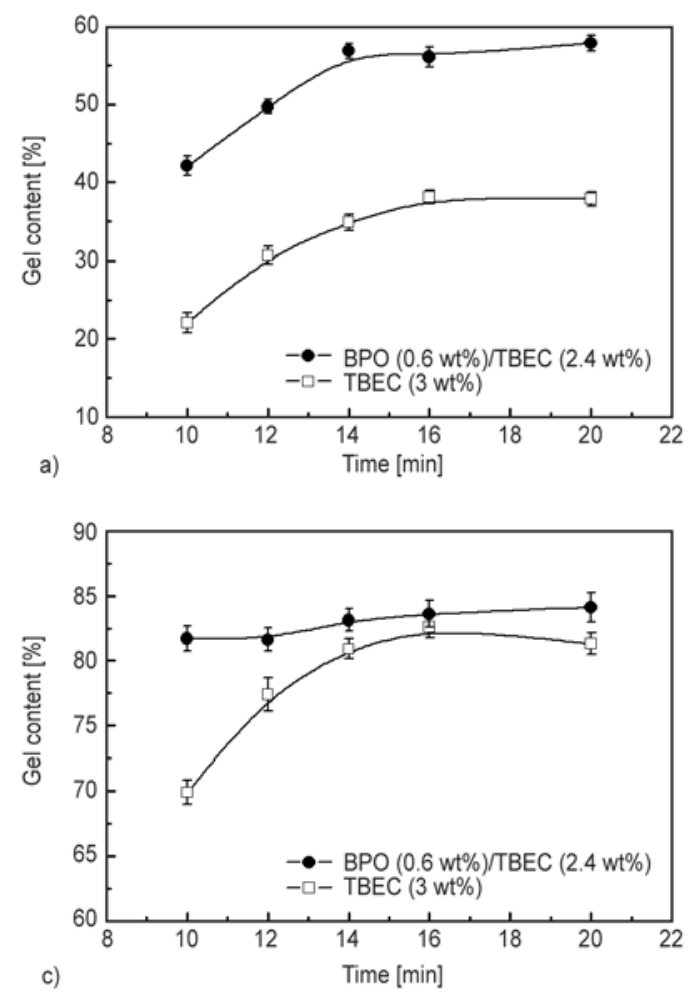

also appears for the curing at $120^{\circ} \mathrm{C}$. Since the gel content at $\mathrm{BPO} / \mathrm{TBEC}$ ratio of $0.8 / 2.2$ resembles that at $0.6 / 2.4$, the latter value is chosen as the optimal one from the viewpoint of economic benefit considering that BPO is much cheaper than TBEC. Figure 2 further reveals the effect of curing time. The gel content of cured EVA films increases with increasing curing time as usual. The most interesting issue lies in the fact that for the curing temperature from 110 to $130^{\circ} \mathrm{C}$, the gel content of the EVA films cured by BPO/TBEC is higher than that of the EVA films cured only by TBEC. When the curing temperature is raised to $140^{\circ} \mathrm{C}$, the TBEC cured EVA films possess higher gel content. These phenomena imply that BPO serves as an accelerator for TBEC, which reduces both curing time and curing temperature of EVA system. Synergy between dual curing agent can be used to explain this phenomenon that the low temperature curing agent was decomposed to initiate the curing, increasing local temperature of the polymer owing to the exotherm. Then, decomposition of the high temperature curing agent is triggered, which further increase the curing rate [8]. Consequently, the gel content of the EVA films cured by the dual curing agent at $130^{\circ} \mathrm{C}$ is almost the same as that cured by TBEC alone at $140^{\circ} \mathrm{C}(\mathrm{cf}$. Figure $2 \mathrm{c}$ and $2 \mathrm{~d}$ ).
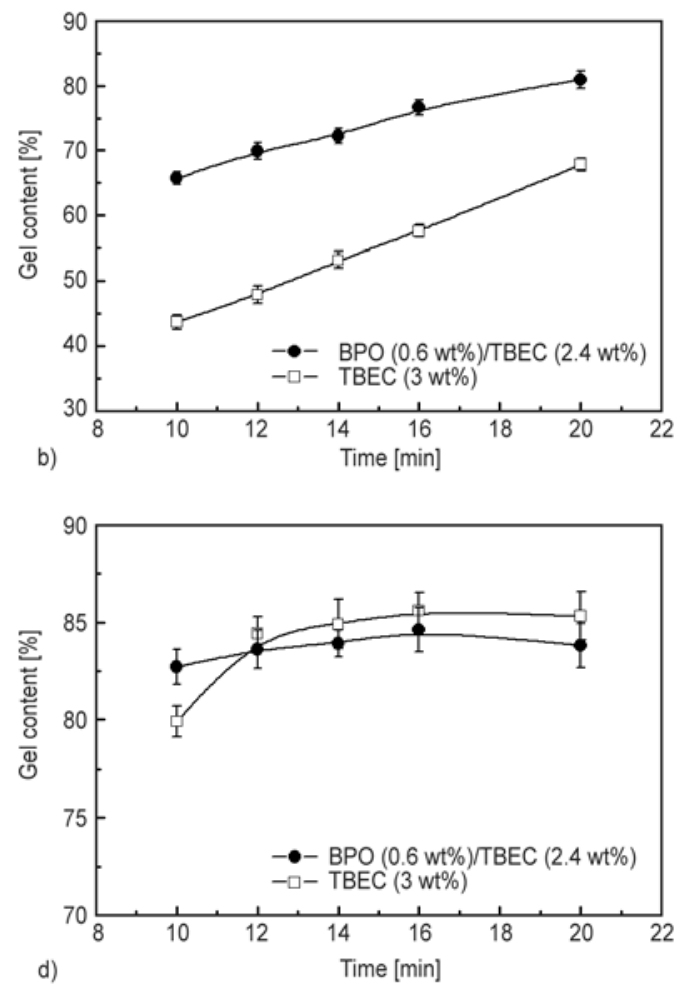

Figure 2. Gel contents of EVA films cured for different times. Curing temperature: (a) $110^{\circ} \mathrm{C}$, (b) $120^{\circ} \mathrm{C}$, (c) $130^{\circ} \mathrm{C}$, and (d) $140^{\circ} \mathrm{C}$ 
Since a gel content of $80 \%$ fits the requirements of practical usage, the optimum curing conditions can thus be determined: curing temperature $=130^{\circ} \mathrm{C}$, curing time $=12 \mathrm{~min}$, and $\mathrm{BPO} / \mathrm{TBEC}=0.6 / 2.4$, which will be applied in the subsequent tests.

Crosslinked networks are built up in the course of curing, which must affect rheological behavior of the polymer. Examination of changes in torque as a function of time would in turn gives us some insight into the curing behavior. Figure 3 shows that following the feeding peak at the beginning, the torque of EVA increases with time due to viscosity increase originating from curing reaction. The torque reaches maximum when curing completes, and then decreases with further increasing time. Figure $3 \mathrm{a}$ exhibits that for the curing temperature of $110^{\circ} \mathrm{C}$, the torque of EVA cured by BPO/TBEC increases more rapidly than that by TBEC. The curing time corresponding to the maximum torque, $t_{\mathrm{c}}[12,13]$, of EVA with $\mathrm{BPO} / \mathrm{TBEC}$ is $9.5 \mathrm{~min}$, while that with TBEC is more than $20 \mathrm{~min}$. In the case of higher curing temperature, the difference of rheological behavior between EVA with BPO/TBEC and EVA with TBEC declines, as characterized by the more and more smaller difference in $t_{c}$. Clearly, BPO takes effect in the dual curing agent system within a relatively wide temperature range. Even in the case of $140^{\circ} \mathrm{C}$, its accelerating role is still perceived.
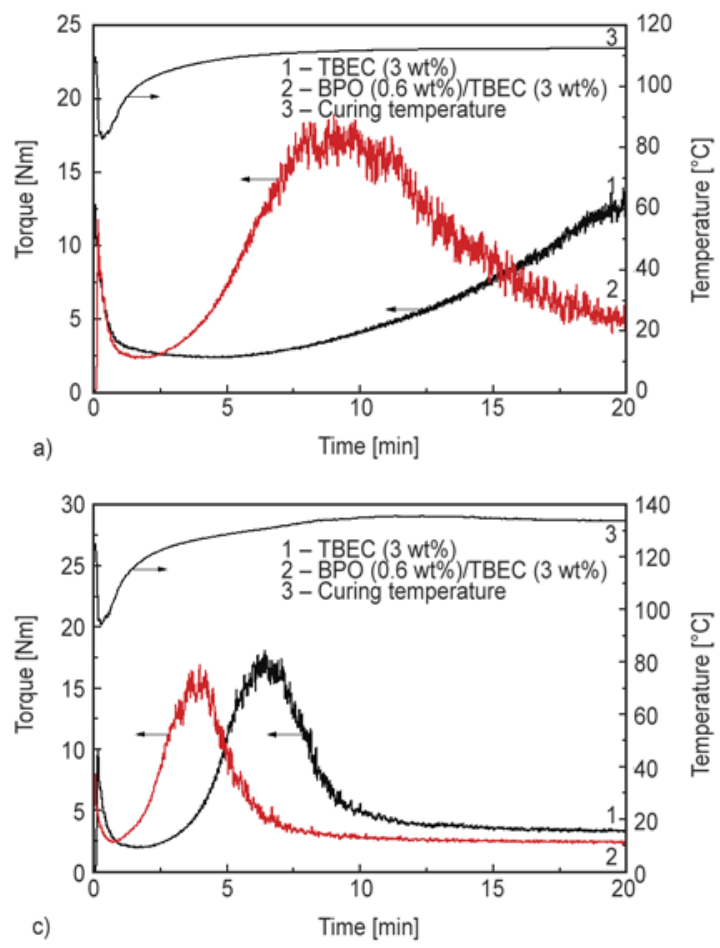

To investigate curing kinetics of the EVA system, DSC measurements were conducted. It can be observed from Figure 4 that there are several transitions during heating of EVA containing curing agents. Two exothermic peaks appear in the region of $40-80^{\circ} \mathrm{C}$, one of which at about $50^{\circ} \mathrm{C}$ is attributed to a secondary crystallization, whereas the peak around $65-70^{\circ} \mathrm{C}$ is the thermo-dynamical melting point of the PE crystallites of EVA [14-16]. The curing of EVA occurs in the region of $100-180^{\circ} \mathrm{C}$ by the emergence of a double exothermic peak. For EVA with TBEC, enthalpy of the endothermic peak at $125^{\circ} \mathrm{C}$ is $0.48 \mathrm{~J} / \mathrm{g}$ and that of the endothermic peak at $150^{\circ} \mathrm{C}$ is $15.9 \mathrm{~J} / \mathrm{g}$. The latter corresponds to the decomposition of TBEC. When the curing agent is replaced by BPO/TBEC, enthalpy of the endother-

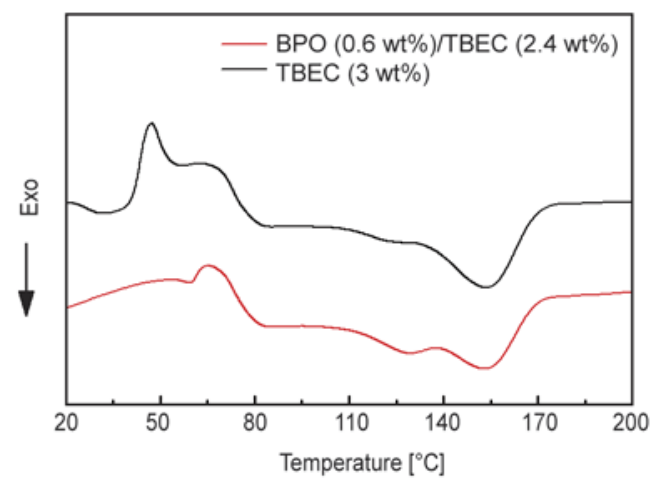

Figure 4. DSC heating curves of EVA with different curing agents recorded at a heating rate of $3{ }^{\circ} \mathrm{C} / \mathrm{min}$
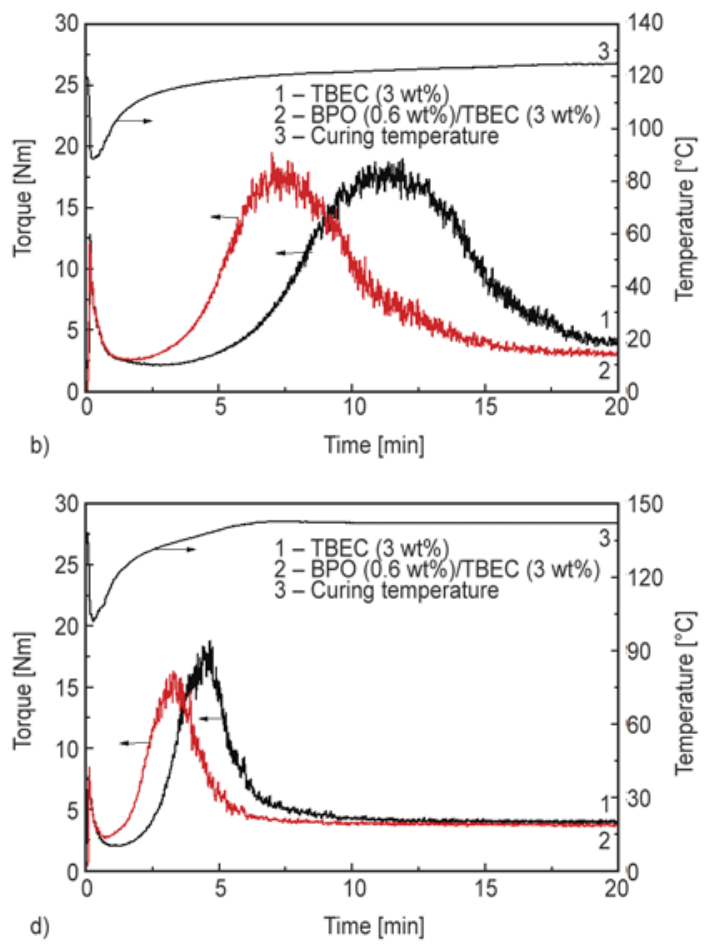

Figure 3. Torque versus time of EVA cured at different curing temperatures: a) $110^{\circ} \mathrm{C}$, b) $120^{\circ} \mathrm{C}$, c) $130^{\circ} \mathrm{C}$, d) $140^{\circ} \mathrm{C}$ 

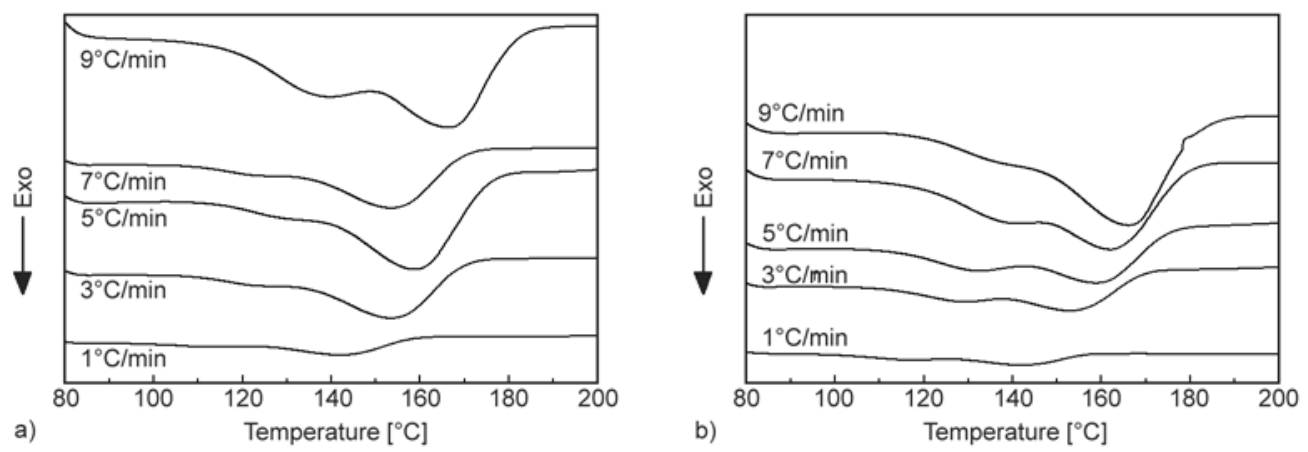

Figure 5. DSC heating curves of EVA containing (a) TEBC (3 wt $\%)$ and (b) BPO $(0.6 \mathrm{wt} \%) / \mathrm{TEBC}(2.4 \mathrm{wt} \%)$ recorded at different heating rates

Table 1. Curing kinetics characteristics of EVA films at different heating rates tested by DSC

\begin{tabular}{|l|c|c|c|c|c|c|c|c|c|c|}
\hline & \multicolumn{4}{|c|}{$\begin{array}{c}\text { EVA film with TBEC } \\
\text { (EVA:TBEC = 100:3) }\end{array}$} & \multicolumn{5}{c|}{$\begin{array}{c}\text { EVA film with BPO/TBEC } \\
\text { (EVA:BPO:TBEC = 100:0.6:2.4) }\end{array}$} \\
\hline \multicolumn{1}{|c|}{$\mathbf{\beta}$} & $\mathbf{1}$ & $\mathbf{3}$ & $\mathbf{5}$ & $\mathbf{7}$ & $\mathbf{9}$ & $\mathbf{1}$ & $\mathbf{3}$ & $\mathbf{5}$ & $\mathbf{7}$ & $\mathbf{9 0}$ \\
\hline$T_{\mathrm{i}}^{*}[\mathrm{~K}]$ & 370.46 & 382.59 & 387.73 & 387.47 & 391.09 & 355.57 & 383.61 & 387.98 & 390.23 & 392.06 \\
\hline$T_{\mathrm{p}}[\mathrm{K}]$ & 416.19 & 427.67 & 433.26 & 436.55 & 440.45 & 414.98 & 426.61 & 433.75 & 436.19 & 439.65 \\
\hline$T_{\mathrm{f}}^{*}[\mathrm{~K}]$ & 432.20 & 445.36 & 450.21 & 454.32 & 455.97 & 429.42 & 443.01 & 448.43 & 452.59 & 458.80 \\
\hline
\end{tabular}

$* T_{\mathrm{i}}$ is the start temperature of curing and $T_{\mathrm{f}}$ is the end temperature of curing

mic peak at $125^{\circ} \mathrm{C}$ becomes $2.1 \mathrm{~J} / \mathrm{g}$. In combination with the above results of torque rheometer, a conclusion can be drawn that decomposition of BPO indeed initiates the curing of EVA at lower temperature and accelerates the curing of EVA as expected. Further research on curing kinetics of EVA films was also carried out by DSC at different dynamic heating rate (Figure 5) and corresponding kinetics characteristics are listed in Table 1.

The activation energy used to reflect the curing rate can be calculated by classic Kissinger equation (Equation (2)) [17] according to the data in Table 1:

$$
-\ln \frac{\beta}{T_{\mathrm{p}}^{2}}=-\ln A+\frac{E_{\alpha}}{R T}
$$

$R$ is the gas constant, $T_{\mathrm{p}}$ is the Kelvin temperature, $A$ and $E_{\alpha}$ are material constants. The constant $E_{\alpha}$,

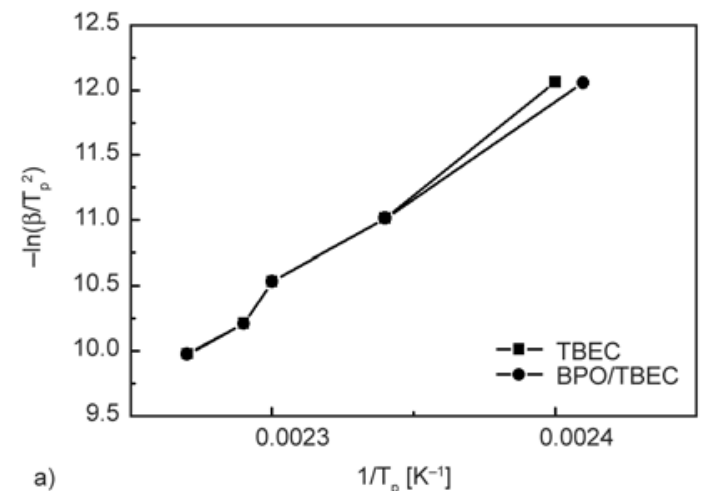

called the activation energy, is often interpreted as the energy barrier opposing the reaction. The constant $A$, most often called the frequency factor, is a measure of the probability that a molecule having energy $E_{\alpha}$ will participate in a reaction.

Plotted $-\ln \beta / T_{\mathrm{p}}^{2}$ versus $1 / T_{\mathrm{p}}$ curve in Figure 6a give a straight line with a slope of $-E_{\alpha} / R$. Caculated $E_{\alpha}$ for EVA film with TBEC and EVA film with BPO/ TBEC were listed in Table 2.

Table 2. Curing activation energies of EVA respectively cured by TBEC and BPO/TBEC

\begin{tabular}{|l|c|c|}
\hline \multicolumn{1}{|c|}{ Content of curing agent } & $\begin{array}{c}\text { Kissinger } \\
{[\mathbf{J} / \mathbf{m o l}]}\end{array}$ & $\begin{array}{c}\text { Ozawa } \\
{[\mathbf{J} / \mathbf{m o l}]}\end{array}$ \\
\hline TBEC $(3 \mathrm{wt} \%)$ & 132.9 & 133.0 \\
\hline $\mathrm{BPO}(0.6 \mathrm{wt} \%) /$ TBEC $(2.4 \mathrm{wt} \%)$ & 123.2 & 123.7 \\
\hline
\end{tabular}

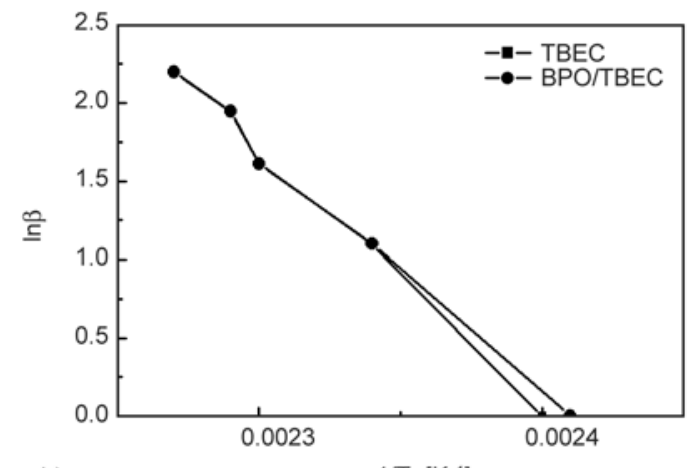

b)

$1 / T_{p}\left[K^{-1}\right]$

Figure 6. Corresponding data obtained from DSC caculation for EVA films: a) curves for Kissinger equation, b) curves for Ozawa equation 
Table 3. Light-transmittance and haze values of EVA films cured with different curing agents

\begin{tabular}{|l|c|c|}
\hline \multicolumn{1}{|c|}{ Content of curing agent } & $\begin{array}{c}\text { Light- } \\
\text { transmittance } \\
{[\%]}\end{array}$ & $\begin{array}{c}\text { Haze value } \\
{[\%]}\end{array}$ \\
\hline TBEC $(3 \mathrm{wt} \%)$ & $91.0( \pm 0.04)$ & $0.33( \pm 0.006)$ \\
\hline $\mathrm{BPO}(0.2 \mathrm{wt} \%) /$ TBEC $(2.8 \mathrm{wt} \%)$ & $90.9( \pm 0.06)$ & $0.34( \pm 0.002)$ \\
\hline $\mathrm{BPO}(0.4 \mathrm{wt} \%) / \mathrm{TBEC}(2.6 \mathrm{wt} \%)$ & $90.8( \pm 0.02)$ & $0.36( \pm 0.004)$ \\
\hline $\mathrm{BPO}(0.6 \mathrm{wt} \%) / \mathrm{TBEC}(2.4 \mathrm{wt} \%)$ & $90.8( \pm 0.02)$ & $0.39( \pm 0.002)$ \\
\hline $\mathrm{BPO}(0.8 \mathrm{wt} \%) / \mathrm{TBEC}(2.2 \mathrm{wt} \%)$ & $90.9( \pm 0.02)$ & $0.38( \pm 0.002)$ \\
\hline $\mathrm{BPO}(1 \mathrm{wt} \%) /$ TBEC $(2 \mathrm{wt} \%)$ & $90.8( \pm 0.04)$ & $0.40( \pm 0.004)$ \\
\hline
\end{tabular}

For comparison, the activation energy was also calculated by Ozawa equation (Equation (3)) [18]. Corresponding $\ln \beta$ versus $1 / T$ curve was plotted in Figure $6 \mathrm{~b}$ and calculated $E_{\alpha}$ were also listed in Table 2:

$\log \beta=\log \frac{A E_{\alpha}}{g(\alpha) R}-2.315-\frac{0.4578 E_{\alpha}}{R T_{\mathrm{p}}}$

As listed in Table 3, the curing activation energies of EVA estimated by the two methods are similar to each other. It means that the data have a high reliability. In the case of dual curing agent, the curing activation energy is $123.7 \mathrm{~J} / \mathrm{mol}$, which is lower than that of EVA cured by TBEC $(133.0 \mathrm{~J} / \mathrm{mol})[19,20]$. It manifests that the curing reaction of EVA becomes easier so that it can be conducted at lower temperature. The accelerating effect of BPO is proved again. Optical losses in a PV module consist of reflection losses and absorption losses of the encapsulations in the front $[21,22]$. After curing, optical properties of EVA films might change. Table 3 shows lighttransmittance and haze values of EVA films after curing. The light-transmittance of the EVA films cured by TBEC is $91.0 \%$ and the haze value is $0.33 \%$. It's fortunately to see that the two parameters of the EVA films with BPO/TBEC are close to those of EVA films without BPO. The addition of BPO particles does not affect optical property of EVA films owing to its decomposition during curing. This ensures application of the EVA films in practice.

In general, EVA films have to be stored in warehouse for a period of time before packaging. During this period, temperature fluctuation might make the pre-compounded curing agents inactivate, especially when the low temperature curing agent is incorporated. (The self-accelerating decomposition temperature of BPO is $83^{\circ} \mathrm{C}$ and its half-life of $10 \mathrm{~h}$

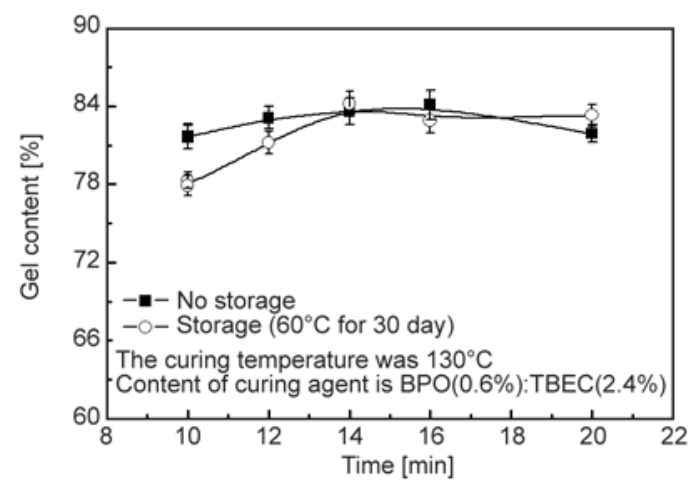

Figure 7. Gel contents of nonstored and stored EVA films cured at $130^{\circ} \mathrm{C}$ for different times

is $72^{\circ} \mathrm{C}$ ). Therefore, curing performance of the EVA films after storage should be checked. Figure 7 compares gel contents of the cured EVA before and after storage at $60^{\circ} \mathrm{C}$. The two plots almost overlap each other. Basically, the gel contents are greater than $80 \%$ regardless of curing time. It is evident that the EVA films with BPO/TBEC have acquired sufficient stability for industrial applications.

\section{Conclusions}

The dual curing agent of BPO/TBEC proves to be able to significantly lower curing temperature and speed up curing process of EVA films as characterized by evolution of gel content and rheology behavior. Because decomposition of peroxide curing agent BPO under lower temperature initiates the curing of EVA and the exotherm further triggers decomposition of the high temperature curing agent TBEC, the curing activation energy of EVA is reduced. Meanwhile, the optical properties of cured EVA films meet the requirements for practical use with light-transmittances of $\sim 91 \%$ and haze values of $\sim 0.35 \%$. On the other hand, the addition of the dual curing agent does not affect storage stability of the EVA films. Crosslinking degree of the EVA films pre-stored at $60^{\circ} \mathrm{C}$ for one month is identical to that of the films without experiencing the storage.

\section{Acknowledgements}

The authors are grateful for the cooperation with Guangzhou Lushan New Materials Co., Ltd. and the support of the Science and Technology Department of Guangdong Province (Grants: 2011A091102003, 2011B090500004, 2011BZ100051, 2011BC100181), Natural Science Foundation of China (Grant: 51173207), and Key Project of Guangdong Education Office (Grant: cxzd1101). 


\section{References}

[1] Pern F. J.: Ethylene-vinyl acetate (EVA) encapsulants for photovoltaic modules: Degradation and discoloration mechanisms and formulation modifications for improved photostability. Die Angewandte Makromolekulare Chemie, 252, 195-216 (1997). DOI: $10.1002 /$ apmc.1997.052520114

[2] Pern F-J., Glick S. H.: Improved photostability of NREL-developed EVA pottant formulations for PV module encapsulation. in 'Proceedings of the $26^{\text {th }}$ IEEE Photovoltaic Specialists Conference, Anaheim, USA' p9 (1997).

[3] Mei Z., Pern F. J., Glick S. H.: Modified EVA encapsulant formulations for low temperature processing. in 'NCPV Program Review Meeting, Lakewood, USA' p4 (2001).

[4] Czanderna A. W., Pern F. J.: Encapsulation of PV modules using ethylene vinyl acetate copolymer as a pottant: A critical review. Solar Energy Materials and Solar Cells, 43, 101-181 (1995).

DOI: 10.1016/0927-0248(95)00150-6

[5] Ganesh B., Unnikrishnan G.: Cure characteristics, morphology, mechanical properties, and aging characteristics of silicone rubber/ethylene vinyl acetate blends. Journal of Applied Polymer Science, 99, 1069-1082 (2006).

DOI: $10.1002 / a p p .22621$

[6] Kajari-Schröder S., Eitner U., Oprisoni C., Alshuth T., Köntges M., Brendel R.: Modelling the curing dynamics of ethylene-vinyl acetate. in 'Proceedings of the $25^{\text {th }}$ European Photovoltaic Solar Energy Conference, Valencia, Spain' 4AV.3.25, p5 (2010).

[7] Beheshty M. H., Nasiri H., Vafayan M.: Gel time and exotherm behaviour studies of an unsaturated polyester resin initiated and promoted with dual systems. Iranian Polymer Journal, 14, 990-999 (2005).

[8] Pern F. J., Czanderna A. W.: Characterization of ethylene vinyl acetate (EVA) encapsulant: Effects of thermal processing and weathering degradation on its discoloration. Solar Energy Materials and Solar Cells, 25, 3-23 (1992).

DOI: 10.1016/0927-0248(92)90013-F

[9] Xia Z. W., Cook D. W.: Exotherm control in the thermal polymerization of nona-ethylene glycol dimethacrylate (NEGDM) using a dual radical initiator system. Polymer, 44, 79-88 (2003).

DOI: 10.1016/S0032-3861(02)00766-8

[10] Yu P., Rong M. Z., Zhang M. Q., Xue H. Y., Ruan W. H.: A EVA (ethylene vinyl acetate) encapsulation film for photovoltaic modules and its preparation method. Chinese Patent, CN102604557 A, China (2003).

[11] ASTM D1003-07: Standard test method for haze and luminous transmittance of transparent plastics (2007).
[12] Bondan F., Soares M. R. F., Bianchi O.: Effect of dynamic cross-linking on phase morphology and dynamic mechanical properties of polyamide 12/ethylene vinyl acetate copolymer blends. Polymer Bulletin, in press (2013). DOI: $10.1007 / \mathrm{s} 00289-013-1051-8$

[13] Kim S-J., Shin B-S., Hong J-L., Cho W-J., Ha C-S.: Reactive compatibilization of the PBT/EVA blend by maleic anhydride. Polymer, 42, 4073-4080 (2001). DOI: 10.1016/S0032-3861(00)00810-7

[14] Hirschl C., Biebl-Rydlo M., DeBiasio M., Mühleisen W., Neumaier L., Scherf W., Oreski G., Eder G., Chernev B., Schwab W., Kraf M.: Determining the degree of crosslinking of ethylene vinyl acetate photovoltaic module encapsulants - A comparative study. Solar Energy Materials and Solar Cells, 116, 203-218 (2013). DOI: $10.1016 /$ j.solmat.2013.04.022

[15] Woo L., Ling M. T. K., Westphal S. P.: Dynamic mechanical studies on secondary relaxations of ethylene copolymers. Thermochimica Acta, 243, 147-154 (1994). DOI: 10.1016/0040-6031(94)85049-6

[16] Androsch R.: Melting and crystallization of poly(ethylene-co-octene) measured by modulated d.s.c. and temperature-resolved X-ray diffraction. Polymer, 40, 2805-2812 (1999).

DOI: 10.1016/S0032-3861(98)00470-4

[17] Kissinger H. E.: Variation of peak temperature with heating rate in differential thermal analysis. Journal of Research of the National Bureau of Standards, 57, 217-221 (1956).

DOI: $10.6028 /$ jres.057.026

[18] Ozawa T.: A new method of analyzing thermogravimetric data. Bulletin of the Chemical Society of Japan, 38, 1881-1886 (1965). DOI: $10.1246 /$ bcsj.38.1881

[19] Stark W., Jaunich M.: Investigation of ethylene/vinyl acetate copolymer (EVA) by thermal analysis DSC and DMA. Polymer Testing, 30, 236-242 (2011). DOI: $10.1016 /$ j.polymertesting.2010.12.003

[20] Agroui K., Maallemi A., Boumaour M., Collins G., Salama M.: Thermal stability of slow and fast cure EVA encapsulant material for photovoltaic module manufacturing process. Solar Energy Materials and Solar Cells, 15, 2509-2514 (2006). DOI: 10.1016/j.solmat.2006.03.023

[21] Khoo Y. S., Walsh T. M., Lu F., Aberle A. G.: Method for quantifying optical parasitic absorptance loss of glass and encapsulant materials of silicon wafer based photovoltaic modules. Solar Energy Materials and Solar Cells, 102, 153-158 (2012). DOI: $10.1016 /$ j.solmat.2012.03.008

[22] Lu Z. H., Yao Q.: Energy analysis of silicon solar cell modules based on an optical model for arbitrary layers. Solar Energy, 81, 636-647 (2007).

DOI: $10.1016 /$ j.solener.2006.08.014 